\title{
Impact of Hypothyroidism on Patients with Hepatocellular Carcinoma Undergoing Liver Transplantation
}

\begin{abstract}
Ahmed Salman, (iD)
Mohamed Aon, (iD) 'Amr Hussein, ${ }^{2}$

Mohamed Salman, (ID) ${ }^{3}$

Mohamed Tourky, iD ${ }^{4}$

Ahmed Mahmoud, ${ }^{5}$

Feras Aljarad, iD 6

Mohamed Elkaseer, ${ }^{7}$ Hossam El-

Din Shaaban, (iD)

Ahmed Moustafa, (iD) 9 Ahmed El-

Mikkawy, ${ }^{10}$ Nahla Gaballa, "'

Heba Abdallah, ${ }^{12}$

Zaky Ftouh Zaky Rashed, (iD) 13,14

Hesham Elkassar

'Internal Medicine Department, Faculty of Medicine, Cairo University, Cairo, Egypt;

${ }^{2}$ Internal Medicine Department, Faculty of

Medicine, Al-Azhar University, Cairo, Egypt;

${ }^{3}$ General Surgery Department, Faculty of

Medicine, Cairo University, Cairo, Egypt;

${ }^{4}$ Department of Surgery, Great Western

Hospitals NHS Foundation Trust, Swindon,

UK; ${ }^{5}$ Senior Clinical Fellow, Great Western

Hospital NHS Foundation Trust, Swindon,

UK; ' ${ }^{6}$ ewisham and Greenwich NHS Trust,

Lewisham, London, UK; ${ }^{7}$ General Surgery

Department, Faculty of Medicine, Al-Azhar

University, Cairo, Egypt; ${ }^{8} \mathrm{Hepatology}$ and

Gastroenterology Department, National

Hepatology and Tropical Medicine Research

Institute, Cairo, Egypt; ${ }^{9}$ Department of

Endemic Medicine and Hepatology, Faculty

of Medicine, Cairo University, Cairo, Egypt;

${ }^{10} \mathrm{Hepatology}$ and Gastroenterology

Department, Theodor Bilharz Research

Institute, Cairo, Egypt; "Anesthesiology and

Intensive Care Department, National Liver

Institute, Menoufia University, Shibin El Kom,

Egypt; ${ }^{12}$ Clinical Pathology Department.

National Liver Institute, Menoufia University,

Shibin El Kom, Egypt; ${ }^{13}$ Anesthesiology and

Intensive Care Department, Faculty of

Medicine, Al-Azhar University, Cairo, Egypt;

${ }^{14}$ Department of Anesthesia, College of

Applied Sciences, Almaarefa university, Ad

Diriyah, Riyadh, Saudi Arabia
\end{abstract}

Correspondence: Ahmed Salman Internal Medicine Department, Faculty of

Medicine, Cairo University, Egypt

$\mathrm{Tel}+201000468664$

Email awea844@gmail.com
Background: This work endeavored to explore the effect of hypothyroidism on mortality in subjects with HCC who underwent living-donor liver transplantation (LDLT).

Methods: This prospective study included 107 patients with HCC subjected to LDLT, divided into hypothyroid group $(n=53)$ and euthyroid group $(n=54)$. The primary objectives were overall and disease-free survival (DFS).

Results: Euthyroid and hypothyroid groups were comparable in all baseline characteristics except the age of patients. Overall survival (OS) of the whole group at 48 months was $68.8 \%$, while the DFS was $60.2 \%$. On univariate analysis, OS was negatively affected by the older age of the patients $(\mathrm{p}<0.001)$ or the donor $(\mathrm{p}<0.001)$, hypothyroidism $(\mathrm{p}=0.008), \mathrm{HBV}$ $(p=0.029)$, larger tumor size $(p=0.023)$, and defective Milan criteria $(p=0.022)$. On multivariate analysis, the age of the patients and donors was the independent factor affecting OS. On univariate analysis, DFS was negatively affected by older age of the patients $(p<0.001)$ or the donor $(\mathrm{p}=0.005)$, hypothyroidism $(\mathrm{p}=0.005)$, HBV $(\mathrm{p}=0.019)$, larger tumor size $(\mathrm{p}=0.023)$, and defective Milan criteria $(\mathrm{p}=0.020)$. On multivariate analysis, the age of the patients, thyroid status, and Milan criteria were the independent factors affecting DFS.

Conclusion: Hypothyroidism is a risk factor for worse outcomes in HCC patients after liver transplantation.

Keywords: hypothyroidism, hepatocellular carcinoma, liver transplantation

\section{Introduction}

Globally, hepatocellular carcinoma $(\mathrm{HCC})$ is the most frequent primary liver cancer representing the sixth most common malignancy. ${ }^{1}$ In Egypt, HCC is the fourth common cancer. $^{2}$ The age-standardized incidence rate of HCC is 61.8 per 100,000 population. ${ }^{3}$ The pathogenesis of HCC is a complex process linked to different predisposing factors. Liver cirrhosis is a chief risk factor for HCC development irrespective of its cause. Meanwhile, chronic viral infections, hepatitis B virus (HBV), and hepatitis $\mathrm{C}$ virus (HCV) are substantial risk factors for $\mathrm{HCC}{ }^{4}$ Metabolic $^{5}$ and hormonal factors ${ }^{6}$ were suggested to be implicated in the development of HCC.

Growing evidence indicated the involvement of thyroid hormones in the development of malignancies of the breast, ${ }^{7}$ ovary, ${ }^{8}$ and HCC. ${ }^{9}$ Thyroid hormones (TH) are involved in regulating several physiological processes, such as cell development, structure, growth, and metabolism. ${ }^{10}$ Thyroid disorders are commonly linked to many chronic comorbidities like diabetes mellitus, ${ }^{11}$ chronic kidney disease, ${ }^{12}$ 
and liver disorders. ${ }^{13}$ Epidemiological data supposed a positive correlation between hypothyroidism and high risk of NAFLD and HCC. ${ }^{14-16}$ Besides, experimental studies found that treatment with $\mathrm{T} 3$ can prevent liver diseases, including $\mathrm{HCC}$ in rodents exposed to carcinogens. ${ }^{17,18}$

These findings back a possible role $\mathrm{TH}$ in the progression and survival in patients with HCC. Therefore, the current work endeavored to explore the effect of hypothyroidism on mortality in patients with HCC undergoing liver transplantation.

\section{Patients and Methods}

This prospective multicentre cohort analysis involved 107 cases aged 18 years or more with HCC who underwent living-donor liver transplantation. The patients were divided into two groups according to the thyroid status: hypothyroid group $(n=53)$ and euthyroid group $(n=54)$. Patients were excluded if diagnosed with cholangiocarcinoma (CCA), mixed HCC, and CCA or fibrolamellar HCC based on explant pathology. Also, patients who developed hypothyroidism due to treatment of hyperthyroidism were not enrolled in the analysis.

The work was approved by the relevant ethical committee of Cairo and Al-Azhar University Hospitals and the National Liver Institute. All living-donor transplants were donated voluntarily with written informed consent, and that this was conducted in accordance with the Declaration of Istanbul. Also, this study was conducted in accordance with the Declaration of Helsinki.

The confirmation of HCC was based on either noninvasive parameters (a new lesion $>1 \mathrm{~cm}$ in size evolving in a cirrhotic patient and depicted by arterial hyperenhancement and portal venous washout on computed tomography, magnetic resonance imaging, or angiography) or histopathology from the biopsy or the explanted liver, adopting the criteria of the American Association for the Study of Liver Disease (AASLD) 2010 Guidelines for HCC. ${ }^{19}$ All cases were followed up for a median of 43 months (range: $1-58$ ).

\section{Data Collection}

Demographic data, medical background, smoking history, laboratory workup, original liver disorders (including symptoms that indicate decompensation such as repeated spontaneous bacterial peritonitis (SBP), repeated hepatic coma, refractory fluid retention, and recurrent variceal bleeding), and HCC features from the explanted liver were registered. Medical history before the diagnosis of HCC, such as uncontrolled blood sugar, elevated blood pressure, hyperlipidemia, and hypothyroidism, were collected.

Pretransplant hypothyroidism was determined as a thyroid-stimulating hormone (TSH) level continuously over the year preceding transplant $>5 \mathrm{mIU} / \mathrm{L}$, a previously confirmed endocrinologist diagnosis, or the usage of thyroid hormone replacement medications. ${ }^{20}$

Original hepatic diseases were confirmed by positive HBsAg for HBV, positive HCV RNA or anti-HCV for $\mathrm{HCV}$, previous undue alcohol consumption for alcoholic liver disease (ALD), metabolic syndrome associated with fatty infiltration for non-alcoholic fatty liver disease (NAFLD), and immunological and/or histopathologic confirmation for autoimmune liver diseases (AILD) including autoimmune hepatitis, primary biliary cholangitis, primary sclerosis cholangitis, and others. Cases were followed up for five years from the time of liver transplantation or till death.

The primary outcomes were overall and disease-free survival and recurrence rate. Overall survival was calculated from the time of operation to the time of death or last follow-up visit. Disease-free survival was calculated from the time of operation to the time of recurrence, death, or last follow-up.

\section{Anesthetic Management}

During the transplantation procedure, all patients were anesthetized by IV propofol $(2 \mathrm{mg} / \mathrm{kg}$ ), Fentanyl (2mic/ $\mathrm{kg})$, and rocuronium $(0.9 \mathrm{mg} / \mathrm{kg})$ as a neuromuscular blocker, and blouses were given according to neuromuscular monitor and maintained by inhaled sevoflurane.

Lungs will be controlled by pressure-regulated volumecontrolled mode, with a mixture of (Fio2 0.4) in air, and PEEP was applied after recruitment, $\mathrm{PaCo} 2$ was adjusted around $35 \mathrm{mmHg}$.

Rotational thromboelastometry (ROTEM) was used to guide transfusion of platelets, fresh frozen plasma, and cryoprecipitate perioperatively.

\section{Sample Size}

In a recent work, ${ }^{21}$ the median survival time of euthyroid cases was nearly 12 years, the accrual interval was one year, and additional follow-up after the accrual interval of 15 years. If the true hazard ratio (relative risk) of hypothyroid cases relative to euthyroid cases is $2.45,48$ hypothyroid patients and 48 euthyroid (total 96) patients 
Table I Baseline Data of the Two Studied Groups

\begin{tabular}{|l|c|c|c|}
\hline & Euthyroid Group n=54 & Hypothyroid Group n=53 & p-value \\
\hline Age (years) & $46.3 \pm 5.8$ & $49.6 \pm 6.6$ & 0.007 \\
\hline Sex (male/female) & $43 / 11$ & $42 / 11$ & 0.961 \\
\hline Diabetes Mellitus & $17(31.5 \%)$ & $17(32.1 \%)$ & 0.947 \\
\hline Hypertension & $8(14.8 \%)$ & $6(11.3 \%)$ & 0.592 \\
\hline Dyslipidemia & $11(20.4 \%)$ & $13(24.5 \%)$ & 0.606 \\
\hline Smoking & $14(25.9 \%)$ & $13(24.5 \%)$ & 0.868 \\
\hline Body mass index (kg/m $\left.{ }^{2}\right)$ & $27.9 \pm 2.9$ & $26.9 \pm 3.6$ & 0.153 \\
\hline Etiology & $23(43.4 \%)$ & $24(44.4 \%)$ & $8(14.8 \%)$ \\
HCV & $10(18.9 \%)$ & $6(11.1 \%)$ & $7(13.0 \%)$ \\
HBV & $6(11.3 \%)$ & $4(7.4 \%)$ & $4(7.4 \%)$ \\
Alcoholic liver disease & $9(17.0 \%)$ & $31.0 \pm 6.0$ & 0.959 \\
NAFLD & $4(7.5 \%)$ & $2(3.8 \%)$ & \\
Autoimmune liver disease & $29.9 \pm 5.1$ & & \\
Other etiology & & & \\
\hline Donor Age (years) & & & \\
\hline
\end{tabular}

Note: Data are summarized as mean \pm SD or Number (\%).

Abbreviations: HCV, Hepatitis C virus; HBV, Hepatitis B virus; NAFLD, non-alcoholic fatty liver disease.

were needed to be able to reject the null hypothesis that the hypothyroid and euthyroid survival curves are equal with a power of 0.80 . An additional $10 \%$ was added to compensate for expected losses; the total sample is 107 patients (53 per group). The Type-I error probability associated with this test of this null hypothesis is 0.05 . The sample size was estimated using power and sample program version 3.1.2.

\section{Statistical Methodology}

Statistical analysis was performed using IBM(C SPSSC Statistics version 22 (IBM(C Corp., Armonk, NY, USA). Comparison between categorical variables was made by Chi-square test. Comparison between arms of numerical variables was done by $t$-test for normally distributed data and Mann-Whitney $U$-test for non-normally distributed data. Survival analysis was done using the Kaplan-Meier method. Comparison between two survival curves was done using Log rank test. Cox proportional hazard analysis was conducted to detect independent variables affecting survival. All tests were two-tailed. A p-value $<0.05$ was considered statistically significant.

\section{Results}

Follow-up started immediately post-transplantation. Cases were followed up for five years from the time of liver transplantation or till death.

The euthyroid and hypothyroid groups were comparable in all of the baseline characteristics except for the age of the patients (Table 1). The hypothyroid group was significantly older than the euthyroid group $(p=0.007)$. There were no considerable differences between the two groups in terms of all of the tumor characteristics and laboratory tests (Tables 2 and 3). TSH levels were significantly higher in the hypothyroid group, as this was the basis of group categorization.

The overall survival of the whole group at 48 months was $68.8 \%$, while the DFS was $60.2 \%$ (Table 4). On univariate analysis overall survival was negatively affected by older age of the patients $(\mathrm{p}<0.001)$ or the donor ( $\mathrm{p}<$ $0.001)$, hypothyroidism $(\mathrm{p}=0.008)$, HBV $(\mathrm{p}=0.029)$, larger tumor size $(\mathrm{p}=0.023)$, defective Milan criteria $(\mathrm{p}$ $=0.022)$, and recurrent gastrointestinal bleeding $(\mathrm{p}=$ 0.036). On multivariate analysis, the age of the patients and donors were the independent factors affecting overall survival (Table 5). 
Table 2 Tumor Characteristics of the Two Studied Groups

\begin{tabular}{|c|c|c|c|}
\hline & $\begin{array}{c}\text { Euthyroid Group } \\
n=54\end{array}$ & $\begin{array}{l}\text { Hypothyroid Group } \\
\qquad n=53\end{array}$ & p-value \\
\hline \multicolumn{4}{|l|}{ Differentiation } \\
\hline No viable tumor & II (20.4\%) & $12(22.6 \%)$ & 0.793 \\
\hline Well and moderate & $31(57.4 \%)$ & $27(50.9 \%)$ & \\
\hline Poorly and undifferentiated & $12(22.2 \%)$ & $14(26.4 \%)$ & \\
\hline \multicolumn{4}{|l|}{ Tumor number } \\
\hline Solitary & $29(53.7 \%)$ & $24(45.3 \%)$ & 0.311 \\
\hline Two & $14(25.9 \%)$ & $21(39.6 \%)$ & \\
\hline More than two & II (20.4\%) & $8(15.1 \%)$ & \\
\hline \multicolumn{4}{|l|}{ Tumor diameter } \\
\hline$<3 \mathrm{~cm}$ & $25(46.3 \%)$ & $24(50.9 \%)$ & 0.463 \\
\hline $3-5 \mathrm{~cm}$ & 21 (38.9\%) & $15(28.3 \%)$ & \\
\hline$>5 \mathrm{~cm}$ & $8(14.8 \%)$ & II (20.8\%) & \\
\hline Within Milan criteria & 48 (88.9\%) & $46(86.8 \%)$ & 0.740 \\
\hline Vascular invasion & $4(7.4 \%)$ & $6(11.3 \%)$ & 0.487 \\
\hline Recurrent Spontaneous peritonitis & II (20.4\%) & $13(24.5 \%)$ & 0.606 \\
\hline Recurrent GI Bleeding & II (20.4\%) & $12(22.6 \%)$ & 0.775 \\
\hline Recurrent encephalopathy & $9(16.7 \%)$ & $8(15.1 \%)$ & 0.824 \\
\hline Resistant Ascites & $6(11.1 \%)$ & $5(9.4 \%)$ & 0.775 \\
\hline Bridge treatment & 19 (35.2\%) & 20 (37.7\%) & 0.784 \\
\hline
\end{tabular}

Note: Data are summarized as Number (\%).

Abbreviation: Gl, gastrointestinal.

Table 3 Results of Laboratory Tests of the Two Studied Groups

\begin{tabular}{|c|c|c|c|}
\hline & $\begin{array}{c}\text { Euthyroid Group } \\
\qquad n=54\end{array}$ & $\begin{array}{l}\text { Hypothyroid Group } \\
n=53\end{array}$ & p-value \\
\hline TSH (mlU/L) & $2.4 \pm 0.7$ & $4.2 \pm 1.3$ & $<0.001$ \\
\hline Hemoglobin (gm/dL) & $9.7 \pm 1.1$ & $9.6 \pm 1.2$ & 0.790 \\
\hline Total leukocytic count $\left(\times 10^{3} / \mathrm{mm}^{3}\right)$ & $7.3 \pm 1.9$ & $7.9 \pm 2.0$ & 0.132 \\
\hline Platelets count $\left(\times 10^{3} / \mathrm{mm}^{3}\right)$ & $187.0(59.0-422.0)$ & I $76.0(46.0-387.0)$ & 0.803 \\
\hline Serum Albumin (mg/dL) & $3.1 \pm 0.6$ & $3.2 \pm 0.6$ & 0.567 \\
\hline Total bilirubin (mg/dL) & $2.0 \pm 0.4$ & $2.0 \pm 0.5$ & 0.436 \\
\hline AST (IU/L) & $62.0(34.0-87.0)$ & $55.0(32.0-110.0)$ & 0.104 \\
\hline ALT (IU/L) & $45.5(25.0-78.0)$ & $43.0(24.0-84.0)$ & 0.201 \\
\hline INR & $1.7 \pm 0.3$ & $1.8 \pm 0.3$ & 0.457 \\
\hline Alpha fetoprotein (IU) & $74.0(12.0-453.0)$ & $68.0(10.0-365.0)$ & 0.866 \\
\hline Glomerular filtration rate & $87.1 \pm 11.4$ & $86.8 \pm 10.5$ & 0.870 \\
\hline MELD score & $14.2 \pm 2.2$ & $14.2 \pm 2.3$ & 0.900 \\
\hline
\end{tabular}

Note: Data are presented as mean \pm SD.

Abbreviations: TSH, Thyroid-stimulating Hormone; AST, Aspartate aminotransferase; ALT, Alanine aminotransferase; INR, The international normalized ratio; MELD, Model for End-stage Liver Disease. 
Table 4 Cumulative Overall and Disease-Free Survival Proportion of the Two Studied Groups in Relation to the Possible Patient and Tumor Factors

\begin{tabular}{|c|c|c|c|c|c|c|}
\hline & & $\mathbf{n}$ & $\begin{array}{l}\text { Cumulative OS } \\
\text { at } 48 \text { Months (\%) }\end{array}$ & p-value & $\begin{array}{l}\text { Cumulative DFS } \\
\text { at } 48 \text { Months (\%) }\end{array}$ & p-value \\
\hline Whole Group & & 107 & 68.8 & & 60.2 & \\
\hline \multicolumn{7}{|l|}{ Age (years) } \\
\hline$\leq 50$ & & 77 & 81.7 & & 69.7 & \\
\hline$>50$ & & 30 & 36.5 & $<0.001$ & 37.1 & $<0.001$ \\
\hline \multicolumn{7}{|l|}{ Thyroid Status } \\
\hline Euthyroid & & 54 & 79.9 & 0.008 & 71.9 & 0.005 \\
\hline Hypothyroid & & 53 & 57.5 & & 47.8 & \\
\hline \multicolumn{7}{|l|}{ Donor Age (years) } \\
\hline$\leq 30$ & & 55 & 90.9 & $<0.001$ & 71.8 & 0.005 \\
\hline$>30$ & & 52 & 46.2 & & 48.0 & \\
\hline \multirow[t]{2}{*}{ Diabetes Mellitus } & No & 73 & 71.8 & & 64.4 & \\
\hline & Yes & 34 & 68.5 & 0.938 & 66.1 & 0.564 \\
\hline \multirow[t]{2}{*}{ Hypertension } & No & 93 & 74.1 & & 67.3 & \\
\hline & Yes & 14 & 47.1 & 0.116 & 48.2 & 0.186 \\
\hline \multirow[t]{2}{*}{ Dyslipidemia } & No & 83 & 71.8 & & 65.6 & \\
\hline & Yes & 24 & 66.7 & 0.410 & 53.6 & 0.286 \\
\hline \multirow[t]{2}{*}{$\mathrm{HCV}$} & No & 60 & 70.9 & & 65.6 & \\
\hline & Yes & 47 & 65.8 & 0.880 & 51.1 & 0.620 \\
\hline \multirow[t]{2}{*}{ HBV } & No & 89 & 75.3 & & 67.5 & \\
\hline & Yes & 18 & 46.3 & 0.029 & 39.5 & 0.019 \\
\hline \multicolumn{7}{|l|}{ Differentiation } \\
\hline No viable tumor & & 23 & 68.6 & & 59.6 & \\
\hline Well and moderate & & 26 & 58.9 & & 43.8 & \\
\hline $\begin{array}{l}\text { Poorly and } \\
\text { undifferentiated }\end{array}$ & & 58 & 72.6 & 0.298 & 69.0 & 0.098 \\
\hline \multicolumn{7}{|l|}{ Tumor Number } \\
\hline Single & & 53 & 64.7 & & 59.0 & \\
\hline Multiple & & 54 & 72.6 & 0.626 & 59.3 & 0.509 \\
\hline \multicolumn{7}{|l|}{ Tumor Size } \\
\hline$\leq 3 \mathrm{~cm}$ & & 52 & 56.9 & & 54.9 & \\
\hline$>3 \mathrm{~cm}$ & & 55 & 80.3 & 0.023 & 62.5 & 0.232 \\
\hline \multirow[t]{2}{*}{ Within Milan } & No & 13 & 46.2 & & 36.9 & \\
\hline & Yes & 94 & 74.2 & 0.022 & 63.6 & 0.020 \\
\hline \multirow[t]{2}{*}{ Vascular invasion } & No & 97 & 73.1 & & 65.3 & \\
\hline & Yes & 10 & 60.0 & 0.150 & 40.0 & 0.139 \\
\hline \multirow[t]{2}{*}{ Bridge treatment } & No & 68 & 66.5 & & 61.7 & \\
\hline & Yes & 39 & 60.5 & 0.679 & 56.5 & 0.650 \\
\hline \multirow{2}{*}{$\begin{array}{l}\text { Recurrent Spontaneous } \\
\text { peritonitis }\end{array}$} & No & 83 & 74.0 & & 63.8 & \\
\hline & Yes & 24 & 60.0 & 0.248 & 50.6 & 0.314 \\
\hline \multirow[t]{2}{*}{ Recurrent GIT Bleeding } & No & 84 & 74.7 & & 64.3 & \\
\hline & Yes & 23 & 48.5 & 0.036 & 46.4 & 0.087 \\
\hline
\end{tabular}


Table 4 (Continued).

\begin{tabular}{|l|l|c|c|c|c|c|}
\hline & & $\mathbf{n}$ & $\begin{array}{c}\text { Cumulative OS } \\
\text { at } \mathbf{4 8} \text { Months (\%) }\end{array}$ & p-value & $\begin{array}{c}\text { Cumulative DFS } \\
\text { at 48 Months (\%) }\end{array}$ & p-value \\
\hline Recurrent Encephalopathy & No & 90 & 72.8 & & 61.7 & 52.9 \\
& Yes & 17 & 58.8 & 0.096 & 62.1 & 0.222 \\
\hline Resistant Ascites & No & 96 & 74.1 & & 45.5 & 0.184 \\
& Yes & 11 & 45.5 & 0.094 & & \\
\hline
\end{tabular}

Abbreviations: $\mathrm{HCV}$, hepatitis $\mathrm{C}$ virus; $\mathrm{HBV}$, hepatitis $\mathrm{B}$ virus.

On univariate analysis disease-free survival was negatively affected by older age of the patients $(\mathrm{p}<0.001)$ or the donor $(\mathrm{p}=0.005)$, hypothyroidism $(\mathrm{p}=0.005), \operatorname{HBV}(\mathrm{p}=0.019)$, larger tumor size $(\mathrm{p}=0.023)$, and defective Milan criteria $(\mathrm{p}=0.020)$. On multivariate analysis, age of the patients, thyroid status and Milan criteria were the independent factors affecting DFS (Table 5).

\section{Discussion}

This study demonstrated that in patients with HCC undergoing liver transplantation, hypothyroidism is an independent factor that negatively affected disease-free but not overall survival. In these cases, the older age of the patients and liver donors were the independent factors worsening overall survival. Older age of the patients, hypothyroidism and Milan criteria were the independent factors affecting disease-free survival.

A great deal of research indicated a potential role of thyroid hormones in the pathogenesis of various cancer types. A previous study suggested that hyperthyroidism increases the hazard of some solid tumors, while hypothyroidism may decrease aggressiveness or delay the onset of malignancy. ${ }^{22}$ This may be logical as thyroid hormones can exert a tumor-promoting effect. However, an opposite conclusion provoked by a recent systematic review of 14 studies concluded that hypothyroidism was linked to an increased risk of HCC and colorectal cancer and conversely decreased risk of prostate cancer. ${ }^{23}$

In a case-control study, Reddy et al suggested that hypothyroidism is an independent risk factor for developing HCC. This was based on a significantly higher likelihood of hypothyroidism in cases with HCC of unknown etiology than those with known etiology. ${ }^{20}$ A larger casecontrol study, including 420 HCC patients, found that a history of hypothyroidism in women for more than ten years increased the risk of developing HCC. In contrast, this association was not observed in men. ${ }^{16}$

These findings enthused research on the molecular mechanisms through which hypothyroid status may promote tumorigenesis. Circulating thyroid hormones (THs) interact with thyroid hormone receptors (THRs) encoded by the TR $\alpha$ and TR $\beta$ genes. THs exert their effect via two mechanisms; stimulation of target gene expression through TR $\alpha$ and TR $\beta$ and a rapid, transcriptionindependent (nongenomic) effect. ${ }^{24}$ These receptors are liganddependent transcription factors belonging to the nuclear receptors superfamily. ${ }^{25}$ These receptors are reported to affect cell proliferation and malignant transformation. The liver is an important

Table 5 Multivariate Cox Regression Analysis for Independent Factors Affecting Overall and Disease-Free Survival on the Whole Studied Group ( $n=107)$

\begin{tabular}{|l|c|c|c|c|}
\hline & Regression Coefficient (B) & P-value & Hazard Ratio & 95\% Confidence Interval of Hazard Ratio \\
\hline Overall Survival & & & 3.063 & $1.462-6.418$ \\
Recipient age & 1.119 & 0.003 & 5.009 & $1.874-13.389$ \\
Donor age & 1.611 & 0.001 & & $1.062-4.050$ \\
\hline Disease-free Survival & & & 2.074 & $1.374-5.130$ \\
Thyroid status & 0.730 & 0.033 & 2.655 & $1.137-5.593$ \\
Recipient age & 0.977 & 0.004 & 2.521 & 0.023 \\
Within Milan criteria & 0.925 & & \\
\hline
\end{tabular}

Note: All variables mean that the higher values contribute to higher risk. 
target organ of $\mathrm{TH}$; hence, disruption of cellular TH-THRs signals is recognized to initiate liver diseases as chronic hepatitis and HCC. ${ }^{17,26}$ For example, reduced expression of TRs is a common event in many human cancer. ${ }^{16,27-29}$ Inactivating mutations in TRs that block access to the target genes has been detected in $+70 \%$ of HCC patients. ${ }^{30,31}$ Also, v-Erba, a mutant form of THRA missing the ability of ligand binding, is reported to cause HCC in transgenic mice. ${ }^{32}$ In addition to maintaining hepatic homeostasis, the TH-THRs pathway acts as a tumor repressor in the liver. ${ }^{17}$

In the present work, hypothyroidism was an independent factor that impacted disease-free survival in those with HCC after liver transplantation. A plausible explanation for these findings was the data reported by Chi et al, who have shown that disruption of $\mathrm{TH}$ production induced marked progression of diethylnitrosamine (DEN)-induced HCC in a murine model. The administration of $\mathrm{TH}$ resulted in suppressing the carcinogenic process through the activation of autophagy. ${ }^{17}$ Other studies in animal models indicated the critical role of normal autophagic flux in preventing HCC development. ${ }^{33,34}$ Autophagy is a bulk degradation system of the impaired components of aggregated proteins in lysosomes to maintain cellular homeostasis. ${ }^{35}$ In a rat model, the down-regulation of TRs, especially $\operatorname{Tr} \beta$ was an early event of the process of HCC carcinogenesis that heralds neoplastic transformation. ${ }^{36}$

In the current study, we took a step forward to investigate the impact of hypothyroidism on the outcome of HCC patients following liver transplantation. We found a negative effect of hypothyroidism on the survival of HCC patients, but why it was associated with worse outcomes is not clear. Findings of the previous studies focusing on the development of HCC might provide a reasonable explanation of the results of the current study. These studies indicated that hypothyroid status, whenever untreated, could promote HCC progression and consequently worsen overall and disease-free survival.

This study is not without limitations. The restricted sample size of a single-center study should be considered. Besides, the study did not investigate the mechanism by which hypothyroid status may exert its action.

\section{Novelty of the Study}

It is sensible to say that there is very scarce research that addressed the impact of hypothyroidism on patients with HCC after liver transplant. We have found only a single article indicating a poorer overall and recurrence-free survival in HCC patients having liver transplantation in the association of hypothyroidism. ${ }^{21}$ Nonetheless, this study was a retrospective one, including 288 patients.
Notably, among the strengths of this work are the prospective nature and the reasonable number of cases with a pretty extended follow-up period.

Furthermore, the study provided epidemiological evidence that can be a nucleus for further research on the molecular basis of unsatisfactory outcomes associated with hypothyroidism.

We can conclude that hypothyroidism represents a risk factor for worse outcomes in HCC patients after liver transplantation. It was linked to poorer overall survival, and it independently worsens disease-free survival in these patients. More extensive multi-center studies are needed to confirm these findings, which may add a significant addition to the treatment of HCC patients after liver transplantation.

\section{Disclosure}

The authors declare that there is no conflicts of interest in this work.

\section{References}

1. Forner A, Reig M, Bruix J. Hepatocellular carcinoma. Lancet. 2018;391(10127):1301-1314. doi:10.1016/S0140-6736(18)30010-2

2. Global Burden of Disease Liver Cancer Collaboration; Akinyemiju T, Abera S, Ahmed M, et al. The burden of primary liver cancer and underlying etiologies from 1990 to 2015 at the global, regional, and national level: results from the global burden of disease study 2015. JAMA Oncol. 2017;3(12):1683-1691. doi:10.1001/jamaoncol.2017.3055.

3. Ibrahim AS, Khaled HM, Mikhail NN, Baraka H, Kamel H. Cancer incidence in Egypt: results of the national population-based cancer registry program. J Cancer Epidemiol. 2014;2014:437971. doi: $10.1155 / 2014 / 437971$

4. Streba CT, Vere CC, Rogoveanu I, Dan Florescu N. Introductory chapter: etiology and pathogenesis of hepatocellular carcinoma. hepatocellular carcinoma - advances in diagnosis and treatment [Internet]. IntechOpen; 2018 [cited August 25, 2020]. Available from: https:// www.intechopen.com/books/hepatocellular-carcinoma-advances-indiagnosis-and-treatment/introductory-chapter-etiology-and-pathogen esis-of-hepatocellular-carcinoma. Accessed September 8, 2021.

5. Agosti $\mathrm{P}$, Sabbà C, Mazzocca A. Emerging metabolic risk factors in hepatocellular carcinoma and their influence on the liver microenvironment. Biochim Biophys Acta Mol Basis Dis. 2018;1864(2):607-617. doi:10.1016/j.bbadis.2017.11.026

6. El Mahdy Korah T, Abd Elfatah Badr E, Mohamed Emara M, Ahmed Samy Kohla M, Gamal Saad Michael G.Relation between sex hormones and hepatocellular carcinoma. Andrologia. 2016;48(9):948955. doi:10.1111/and.12536

7. Flamini MI, Uzair ID, Pennacchio GE, et al. Thyroid hormone controls breast cancer cell movement via integrin $\alpha \mathrm{V} / \beta 3 / \mathrm{SRC} / \mathrm{FAK} / \mathrm{PI} 3$-kinases. Horm Cancer. 2017;8(1):16-27. doi:10.1007/s12672-016-0280-3

8. Weingarten C, Jenudi Y, Tshuva RY, et al. The interplay between epithelialmesenchymal transition (emt) and the thyroid hormones- $\alpha \mathrm{v} \beta 3$ axis in ovarian cancer. Horm Cancer. 2018;9(1):22-32. doi:10.1007/s12672-0170316-3

9. Martínez-Iglesias O, García-Silva S, Regadera J, Aranda A. Hypothyroidism enhances tumor invasiveness and metastasis development. PLoS One. 2009;4(7):e6428. doi:10.1371/journal.pone.0006428 
10. Oetting A, Yen PM. New insights into thyroid hormone action. Best Pract Res Clin Endocrinol Metab. 2007;21(2):193-208. doi:10.1016/ j.beem.2007.04.004

11. Kadiyala R, Peter R, Okosieme OE. Thyroid dysfunction in patients with diabetes: clinical implications and screening strategies. Int $J$ Clin Pract. 2010;64(8):1130-1139. doi:10.1111/j.17421241.2010.02376.x

12. Rhee CM, Brent GA, Kovesdy CP, et al. Thyroid functional disease: an under-recognized cardiovascular risk factor in kidney disease patients. Nephrol Dial Transplant. 2015;30(5):724-737. doi:10.1093/ndt/gfu024

13. Eshraghian A, Jahromi AH. Non-alcoholic fatty liver disease and thyroid dysfunction: a systematic review. World J Gastroenterol. 2014;20(25):8102-8109. doi:10.3748/wjg.v20.i25.8102

14. Pagadala MR, Zein CO, Dasarathy S, Yerian LM, Lopez R, McCullough AJ. Prevalence of hypothyroidism in non-alcoholic fatty liver disease. Dig Dis Sci. 2012;57(2):528-534. doi:10.1007/ s10620-011-2006-2

15. Xu C, Xu L, Yu C, Miao M, Li Y. Association between thyroid function and non-alcoholic fatty liver disease in euthyroid elderly Chinese. Clin Endocrinol. 2011;75(2):240-246. doi:10.1111/j.13652265.2011.04016.x

16. Hassan MM, Kasab A, Li D, et al. Association between hypothyroidism and hepatocellular carcinoma: a case-control study in the United States. Hepatology. 2009;49(5):1563-1570. doi:10.1002/hep.22793

17. Chi H-C, Chen S-L, Tsai C-Y, et al. Thyroid hormone suppresses hepatocarcinogenesis via DAPK2 and SQSTM1-dependent selective autophagy. Autophagy. 2016;12(12):2271-2285. doi:10.1080/ 15548627.2016.1230583

18. Chi H-C, Chen S-L, Lin S-L, et al. Thyroid hormone protects hepatocytes from $\mathrm{HBx}$-induced carcinogenesis by enhancing mitochondrial turnover. Oncogene. 2017;36(37):5274-5284. doi:10.1038/ onc. 2017.136

19. Bruix J, Sherman M. Management of hepatocellular carcinoma: an update. Hepatology. 2011;53(3):1020-1022. doi:10.1002/hep.24199

20. Reddy A, Dash C, Leerapun A, et al. Hypothyroidism: a possible risk factor for liver cancer in patients with no known underlying cause of liver disease. Clin Gastroenterol Hepatol. 2007;5(1):118-123. doi:10.1016/j.cgh.2006.07.011

21. Zhang N, Jin W, Zhou S, et al. Hypothyroidism is associated with worse outcomes of hepatocellular carcinoma patients after liver transplantation. Cancer Med. 2018;7(12):5870-5878. doi:10.1002/ cam4.1797

22. Krashin E, Piekiełko-Witkowska A, Ellis M, Ashur-Fabian O. Thyroid hormones and cancer: a comprehensive review of preclinical and clinical studies. Front Endocrinol. 2019;10:59. doi:10.3389/ fendo.2019.00059
23. Trodello C, Higgins S, Ahadiat O, Wysong A. Hypothyroidism as a risk factor for cancer: a systematic review and implications for future studies. Cancer Sci Res Open Access. 2017;4(2):1-7.

24. Gnoni GV, Rochira A, Leone A, Damiano F, Marsigliante S, Siculella L. 3,5,3'triiodo-L-thyronine induces SREBP-1 expression by nongenomic actions in human HEP G2 cells. J Cell Physiol. 2012;227 (6):2388-2397. doi:10.1002/jcp.22974

25. Flamant F, Baxter JD, Forrest D, et al. The pharmacology and classification of the nuclear receptor superfamily: thyroid hormone receptors. Pharmacol Rev Int Union Pharmacol. 2006;58:705-711.

26. Lin Y-H, Huang Y-H, Wu M-H, et al. Thyroid hormone suppresses cell proliferation through endoglin-mediated promotion of p21 stability. Oncogene. 2013;32(33):3904-3914. doi:10.1038/onc.2013.5

27. Khan SR, Chaker L, Ruiter R, et al. thyroid function and cancer risk: the Rotterdam study. J Clin Endocrinol Metab. 2016;101(12):50305036. doi:10.1210/jc.2016-2104

28. Mondul AM, Weinstein SJ, Bosworth T, Remaley AT, Virtamo J, Albanes D. Circulating thyroxine, thyroid-stimulating hormone, and hypothyroid status and the risk of prostate cancer. PLoS One. 2012;7 (10):e47730. doi:10.1371/journal.pone.0047730

29. Ortega-Olvera C, Ulloa-Aguirre A, Ángeles-llerenas A, et al. Thyroid hormones and breast cancer association according to menopausal status and body mass index. Breast Cancer Res. 2018;20(1):94. doi:10.1186/s13058-018-1017-8

30. Lin $\mathrm{KH}, \mathrm{Wu} \mathrm{YH}$, Chen SL. Impaired interaction of mutant thyroid hormone receptors associated with human hepatocellular carcinoma with transcriptional Coregulators. Endocrinology. 2001;142(2):653662. doi:10.1210/endo.142.2.7927

31. Chan I, Privalsky M. Thyroid hormone receptors mutated in liver cancer function as distorted antimorphs. Oncogene. 2006;25 (25):3576-3588. doi:10.1038/sj.onc. 1209389

32. Barlow C, Meister B, Lardelli M, Lendahl U, Vennström B. Thyroid abnormalities and hepatocellular carcinoma in mice transgenic for v-erbA. EMBO J. 1994;13(18):4241-4250. doi:10.1002/j.14602075.1994.tb06744.x

33. Takamura A, Komatsu M, Hara T, et al. Autophagy-deficient mice develop multiple liver tumors. Genes Dev. 2011;25(8):795-800. doi:10.1101/gad.2016211

34. Komatsu M. Liver autophagy: physiology and pathology. J Biochem. 2012;152(1):5-15. doi:10.1093/jb/mvs059

35. Kuma A, Hatano M, Matsui M, et al. The role of autophagy during the early neonatal starvation period. Nature. 2004;432(7020):10321036. doi:10.1038/nature03029

36. Frau C, Loi R, Petrelli A, et al. Local hypothyroidism favors the progression of preneoplastic lesions to hepatocellular carcinoma in rats. Hepatology. 2015;61(1):249-259. doi:10.1002/hep.27399
International Journal of General Medicine

\section{Publish your work in this journal}

The International Journal of General Medicine is an international, peer-reviewed open-access journal that focuses on general and internal medicine, pathogenesis, epidemiology, diagnosis, monitoring and treatment protocols. The journal is characterized by the rapid reporting of reviews, original research and clinical studies across all disease areas. The manuscript management system is completely online and includes a very quick and fair peer-review system, which is all easy to use. Visit http://www.dovepress.com/ testimonials.php to read real quotes from published authors. 